\title{
Hemostatic Agents in Combination with Diovine for Local Treatment of Simulated Bleeding Gastric Ulcers
}

\author{
Evgeniy F. Cherednikov, $\mathrm{PhD}, \mathrm{ScD}^{1}$; Alexandr A. Glukhov, $\mathrm{PhD}, \mathrm{ScD}^{1}$; \\ Mikhail N. Romantsov, $\mathrm{PhD}^{1}$; Yuri V. Maleev, $\mathrm{PhD}, \mathrm{ScD}^{2}$; Sergey V. Barannikov, $\mathrm{PhD}^{1}$; \\ Irina A. Shkurina, $\mathrm{PGS}^{1}$; Anastasiya T. Vysotskaya, $\mathrm{PhD}^{1}$; Evgeniy S. Ovsyannikov, $\mathrm{PhD}^{1 *}$ \\ ${ }^{1}$ Voronezh State Medical University named after N. N. Burdenko \\ ${ }^{2}$ Voronezh Basic Medical College \\ Voronezh, the Russian Federation
}

\begin{abstract}
Background: Acute gastroduodenal bleeding is one of the urgent and complex problems of emergency surgery. The objective of our study was to investigate the performance of powder-like hemostatic agents in combination with granular Diovine for bleeding management in experimental gastric ulcers.

Methods and Results: Experimental studies in vivo were conducted on 15 mongrel dogs, using the model of gastric ulcer by E. F. Cherednikov. During esophagogastroscopy, all animals were exposed to 2 bleeding gastric ulcers (experimental and control). Experiments were performed with 30 bleeding gastric ulcers. In experimental ulcers, endoscopic hemostasis was carried out by sufflations on a bleeding defect of powder-like Gelplastan and NovoSeven (lyophilized powder) in combination with Diovine. In control ulcers, endoscopic treatment was not performed. The experimental studies showed that in experimental ulcers, bleeding stopped at 3.9(3.5;4.9) sec $(P<0.001)$; their hemostasis was stable without recurrent bleeding. In control ulcers, bleeding stopped at 27.5(24.0;31.0) $\sec (P<0.001)$ and 5 episodes of recurrent bleeding were noted. The drug composition (Gelplastan, NovoSeven, and Diovine) has a hemostatic effect and accelerates healing processes of experimental bleeding ulcers. A complete healing of experimental gastric ulcers occurred in 8.0(8.0;9.0) days with a moderate scar that does not deform the stomach wall. Complete healing of control gastric ulcers occurred in 15.5(14.0;16.0) $(P<0.001)$ days of observations.

Conclusion: The combined use of Gelplastan, NovoSeven, and Diovine for the local treatment of experimental bleeding gastric ulcers in dogs leads not only to an effective termination of hemorrhage, but also promotes reparative regeneration, synchronization of interaction of cell structures and acceleration of the healing time of simulated ulcers.(International Journal of Biomedicine. 2020;10(2):138-141.)
\end{abstract}

Key Words: experimental gastric ulcer $\bullet$ gastroduodenal bleeding $\bullet$ endoscopic hemostasis $\bullet$ healing processes

\section{Introduction}

Treatment of acute gastroduodenal bleeding (GIB) remains challenging in emergency surgery. A common cause of GIB is acute and chronic ulcers of the stomach and duodenum..$^{(1-5)}$ Bleeding recurrence is the main cause of unsatisfactory results for bleeding management in the upper gastrointestinal tract. ${ }^{(6-8)}$ Endoscopic bleeding management occupies the main place in the treatment of this category of patients..$^{9,10)}$

The outcome of the disease is mainly determined by stable and terminative hemorrhage arrest and by the time of ulcer healing. The search for new medicines and novel drug compositions, and the development of effective methods of endoscopic hemostasis, are urgent tasks for GIB management. . $^{(1-13)}$

The objective of our study was to investigate the performance of powder-like hemostatic agents in combination with granular Diovine for bleeding management in experimental gastric ulcers.

\section{Materials and Methods}

The experiment investigated the powder-like hemostatic agents Gelplastan and NovoSeven, which have not been previously used to stop gastrointestinal bleeding, and granular 
biologically active sorbent Diovine with cytoprotective, hemostatic and antibacterial properties.

Studies were performed on 15 mongrel male and female dogs weighing 9-14 kg. In vivo experiments were carried out in accordance with the legislation of the Russian Federation, in strict compliance with the European Convention for the protection of animals used for experimental and other purposes (Strasbourg, France, 1986), the provisions of Directive 210/63/ EU of the European Parliament and the Council of the European Union of 22 September 2010 on the protection of animals used for scientific purposes (Article 27).

During the stomach endoscopy or esophagogastroduodenoscopy under intravenous anesthesia (Zoletil 100 solution, $7.5 \mathrm{mg} / \mathrm{kg}$ ), all dogs were given an injection of a $96 \%$ ethyl alcohol solution with a $3.0 \mathrm{ml}$-needle into the submucosal layer of the antral part of the stomach along a small curvature; then they were injected with a solution of Vincristine $(0.01 \mathrm{mg} /$ $\mathrm{kg}) .^{(14,15)}$ On Day 4, all dogs demonstrated a typical round ulcer of the stomach reaching the muscle layer of fibrin coating on the bottom with an area of inflammation at the periphery. Moderate bleeding was induced by injuring the edges and bottom of the ulcer with biopsy forceps.

Each dog was subject to 2 bleeding gastric ulcers (control and experimental) at a distance of $4-5 \mathrm{~cm}$ from each other. Thus, all experimental studies were conducted on 30 simulated gastric ulcers.

In the experimental ulcers, endoscopic hemostasis was achieved by applying powder-like Gelplastan and NovoSeven (lyophilized powder) in equal amounts of $0.1 \mathrm{~g}$ in combination with $0.3 \mathrm{~g}$ of Diovine; the next therapeutic endoscopy was performed in 3-4 days.

Control gastric ulcers did not receive treatment; the time of spontaneous bleeding arrest was measured with a stopwatch timer. The outcome measurement involved the following indicators: time of hemorrhage arrest, signs of the hemorrhage recurrence, time of recovery of experimental ulcers, and stomach tissue reaction to applied drugs.

Biopsies of the gastric mucosa were used as a material for morphological study. Histological sections were stained with $\mathrm{H} \& \mathrm{E} / \mathrm{Van}$ Gieson's method, reticular fiber was stained by nitric acid silver, and neutral glycol-proteins were identified in PAS reaction. Histological examination of the sections was performed by light microscopy at magnifications of $\times 100$ and $\times 400$; the cellular component of the connective tissue stroma of the mucous membrane was assessed at $\times 900$ magnification.

Statistical analysis was performed using Microsoft Excel software package. For descriptive analysis, results are presented as mean \pm standard deviation (SD), median (Me), interquartile range $(I Q R)$, minimum and maximum values. Wilcoxon rank sum test was used to test for difference in medians. Group comparisons with respect to categorical variables were performed using Fisher's exact test. A probability value of $P<0.05$ was considered statistically significant.

\section{Results and Discussion}

Experimental studies of the combined use of hemostatic agents (Gelplpstan and NovoSeven) and granular sorbent
(Diovine) demonstrated that applying them to the experimental bleeding surface in the area of the ulcer caused the development of a gel-like matrix of blood-stained hydrogel, which protected the hemostatic agents and ulcers from gastric acid irritation. This matrix remained on the surface of the experimental ulcers up to 4 days due to its adhesive properties. The average time of hemorrhage arrest was $3.91 \pm 1.28 \mathrm{sec}$ in the experimental group and $27.45 \pm 4.5 \mathrm{sec}$ in the control group $(P=0.02)$. The experimental group demonstrated stable and terminative hemostasis. There was no recurrent bleeding or other complications in the experimental ulcers associated with hemostatics in combination with Diovine. In the control ulcers, there were 5 episodes of recurrent bleeding. Hematin points were detected in the bottom of the simulated ulcers in 3 cases, and there was a dark clot in the bottom of the ulcers in 2 cases. These episodes of recurrent bleeding in the control ulcers stopped on their own and did not require any endoscopic interventions.

Dynamic gastroscopy and morphological examinations demonstrated that a combined treatment resulted in a faster reparative processes than in the control bleeding ulcers. The average time for inflammation to subside under hemostatic and sorbent treatment was $3.0(2.0 ; 4.0)$ days in the experimental group and 7.0(6.0;8.0) days in the control group $(P<0.001)$. The average time of purification of the ulcer bottom was $3.0(2.0 ; 4.0)$ days in the experimental group and 5.0(4.0;5.0) days in the control group $(P<0.001)$. It should be noted that the fibrinous-necrotic layer from the bottom of the ulcer was partially removed when ulcerative bleeding was induced during traumatization of the bottom and edges of the ulcer with biopsy forceps. In this regard, the time of ulcer purification is more likely to be associated with Diovine's capacity to prevent inflammation and tissue necrosis than with the removal of fibrinous-necrotic masses.

The anti-inflammatory properties of the granular sorbent in the simulated gastric ulcers can be explained by several points:

First, the layer of the swollen sorbent protects the entire ulcer surface with a hydrogel coating that prevents the peptic action of gastric juice.

Second, the sorption abilities of Diovine cause a decrease in edema in the ulcer area and a decrease in the concentration of bacteria and toxins in the ulcer crater.

Third, the hydrogel coating on the surface of the ulcer after pneumoinsufflation improves blood circulation. It is nonhermetic and does not prevent gas exchange and metabolic processes.

Microscopic examination of gastrobioptates on Day 3 after combination therapy (Gelplastan, NovoSeven, and Diovine) showed edema, and some biopsies showed necrosis or focal mixed-cell infiltration in surface layers of the experimental ulcers. At the same time, in most fields of vision the coverpit epithelium was preserved as high cubic epithelium; the glands are long and straight, with an epithelial lining. On Day 5 of the therapy, the integumentary epithelium was preserved, lymphocytes and monocytes prevailed in the stromal component of the mucous layer, and fibroblasts appeared in the experimental ulcers. 
In the control ulcers, on Day 5 the mucous layer was edematous, the integumentary epithelium was partially desquamated, histiocytes and neutrophils prevailed in the stromal component of the mucous layer, and by Day 15, the number of fibroblasts had increased.

On Day 8 of therapy for the experimental ulcers, the cover-pit epithelium was represented by a high cubic epithelium. The submucosal layer revealed edema, focal fibrosis and scattered mixed-cell infiltration.

On Day 15, the control ulcers showed edematous mucosa edema, mixed-cell infiltration, and fibrin fragments. The intervertebral stroma was also edematous with foci of fibrinoid necrosis. The mucous layer was moderately edematous; intervertebral stroma also revealed foci of edema and fibrosis.

A complete healing of experimental gastric ulcers occurred in 8.0(8.0;9.0) days with a moderate scar that does not deform the stomach wall. Complete healing of control gastric ulcers occurred in $15.5(14.0 ; 16.0)(P<0.001)$ days of observations. At the same time, all control ulcers healed with the development of a severe scar deforming the stomach wall. The efficiency Gelplastan and NovoSeven in combination with Diovine for hemorrhage is presented in the Table 1.

\section{Table 1.}

The performance of Gelplastan and NovoSeven in combination with Diovine for simulated ulcer hemorrhage therapy

\begin{tabular}{|c|c|c|c|}
\hline Variable & $\begin{array}{c}\text { Experimental } \\
\text { ulcers }\end{array}$ & $\begin{array}{l}\text { Control } \\
\text { ulcers }\end{array}$ & $P$-value \\
\hline \multicolumn{4}{|c|}{ Hemostasis performance indicators } \\
\hline $\begin{array}{l}\text { Time of hemorrhage arrest, } \\
\text { sec }\end{array}$ & $\begin{array}{c}3.9 \\
(3.5 ; 4.9) \\
\end{array}$ & $\begin{array}{c}27.5 \\
(24.0 ; 31.0)\end{array}$ & $<0.001$ \\
\hline Number of recurrences & 0 & 5 & 0.04 \\
\hline Final hemostasis & 15 & 10 & 0.04 \\
\hline \multicolumn{4}{|c|}{ Comparative dynamics of reparative processes } \\
\hline $\begin{array}{l}\text { Subsiding of inflammatory } \\
\text { phenomena, days }\end{array}$ & $\begin{array}{c}3.0 \\
(2.0 ; 4.0) \\
\end{array}$ & $\begin{array}{c}7.0 \\
(6.0 ; 8.0) \\
\end{array}$ & $<0.001$ \\
\hline $\begin{array}{l}\text { Purification of the ulcer bottom, } \\
\text { days }\end{array}$ & $\begin{array}{c}3.0 \\
(2.0 ; 4.0) \\
\end{array}$ & $\begin{array}{c}5.0 \\
(4.0 ; 5.0) \\
\end{array}$ & $<0.001$ \\
\hline $\begin{array}{l}\text { Granulation development, } \\
\text { days }\end{array}$ & $\begin{array}{c}2.0 \\
(2.0 ; 3.0) \\
\end{array}$ & $\begin{array}{c}6.0 \\
(5.0 ; 6.0) \\
\end{array}$ & $<0.001$ \\
\hline Epithelization onset, days & $\begin{array}{c}3.0 \\
(3.0 ; 4.0) \\
\end{array}$ & $\begin{array}{c}8.0 \\
(7.0 ; 9.0) \\
\end{array}$ & $<0.001$ \\
\hline $\begin{array}{l}\text { Healing of experimental ulcers, } \\
\text { days }\end{array}$ & $\begin{array}{c}8.0 \\
(8.0 ; 9.0)\end{array}$ & $\begin{array}{c}15.5 \\
(14.0 ; 16.0)\end{array}$ & $<0.001$ \\
\hline
\end{tabular}

Thus, morphological data indicate that combination therapy (Gelplastan, NovoSeven and Diovine) for experimental gastric ulcers contributed to synchronizing the interaction of cell structures and accelerated change of phases of the ulcerative process. Thus, the rapid subsiding of inflammatory phenomena in the experimental ulcers was demonstrated by the low quantity of neutrophils in the cell population. The development of glands that were enlarged and filled with leukocytes on Day 3 of the experiment can be regarded as a positive reaction of the mucous membrane to the hemostatic agents with a granular sorbent. At the same time, it should be noted that during therapy for the experimental ulcers, neither destruction processes nor progression of inflammation in the subsequent periods of observations were revealed. The development of fibroblasts in the granulation tissue of experimental ulcers after Day 5 of treatment can be confirming evidence of the early beginning of the healing process, finalized with a moderate scar. At the same time, in control ulcers, inflammation began to subside only on Day 10, and an increase in the number of fibroblasts was observed on Day 15 of observation and finalized with a severe connective tissue scar.

Summarizing the results of the experimental study, we have concluded that Gelplastan and NovoSeven in combination with Diovine are effective drugs with a good hemostatic effect, providing healing of experimental ulcers. There was neither damage to the stomach tissue nor development of foreign body cells during insufflation of these drugs. Morphological signs of allergy were not detected in any case. Gelplastan and NovoSeven in combination with Diovine were spontaneously rejected during healing of ulcers and were not perceived by the gastric mucosa as a foreign body.

Thus, the powder-like hemostatic agents Gelplastan and NovoSeven in combination with Diovine for the therapy of experimental gastric ulcers contributes to stable hemostasis, reduces the time of hemorrhage, and also eliminates the possibility of recurrent bleeding. The combined use of Gelplastan, NovoSeven, and Diovine for the local treatment of experimental bleeding gastric ulcers in dogs leads not only to an effective termination of hemorrhage, but also promotes reparative regeneration, synchronization of interaction of cell structures and acceleration of the healing time of simulated ulcers.

\section{Competing Interests}

The authors declare that they have no competing interests.

\section{References}

1. Budnevsky AV, Cherednikov EF, Popov AV, Ovsyannikov ES, Kravchenko AY, Fursov KO. A complex multidisciplinary approach to prevention gastro-duodenal bleeding in patients of general hospital. International Journal of Biomedicine. 2017; 7(3):204-207.

2. Shapkin $\mathrm{YuG}$, Potahin SN. [The dynamics of main indicators for treatment of ulcerative gastroduodenal bleeding - the analysis of several years studies]. Saratov Journal of Medical Scientific Research. 2014;10(3):456-460. [Article in Russian].

3. Cherednikov EF, Barannikov SV, Romantsov MN, Popov AV. New aspects of preventive endoscopic hemostasis in the treatment of peptic ulcer bleeding in the experimental condition. The EPMA Journal. 2017;8(S1):45.

*Corresponding author: Evgeniy S. Ovsyannikov, PhD. Department of faculty therapy, Voronezh State Medical University named after N.N. Burdenko. Voronezh, Russia. E-mail: ovses@ yandex.ru 
4. Adianov VV, Cherednikov EF. [Optimization of treatment of gastroduodenal bleeding in patients with high surgical risk]. System Analysis and Management in Biomedical Systems. 2014;13(4):841-846. [Article in Russian].

5. Derjaeva OG, Cherednikov EF. [Multimodality therapy of erosiveulcer gastroduodenal bleeding by patients in a multidisciplinary hospital]. System Analysis and Management in Biomedical Systems. 2014;13(3):725-730. [Article in Russian].

6. Cherednikov EF, Deryaeva OG, Adianov VV, Ovchinnikov IF, Popov AV. [Modern trends of diagnosis and treatment of patients with gastrointestinal bleeding in the centre]. System Analysis and Management in Biomedical Systems. 2014;13(2):426-431. [Article in Russian].

7. Cherednikov EF, Barannikov SV, Maleev YuV, Fursov KO, Litovkina TE, Zakurdaev EI, Ovsyannikov ES. Experimental justification of using Aseptisorb-A and platelet-rich plasma in endoscopic treatment of mold bleeding stomach defects. International Journal of Biomedicine. 2017;7(4):298-301.

8. Cherednikov EF, Deryaeva OG, Ovchinnikov IF, Cherednikov EE, Adianov VV, Bondarenko AA, Yakushev FK. The effectiveness of the modern approach to the treatment of patients with gastroduodenal bleeding in a multidisciplinary hospital. Nauchno-medicinskij vestnik Central'nogo Chernozem'ya. 2016;65:20-25. [Article in Russian].

9. Cherednikov EF, Kashurnikova MA, Romantsov MN, Barannikov SV, Bolkhovitinov A E, Gaponenkov DG, Lubimov PU. [Experimental study of new means of local hemostasis in the treatment of gastric bleeding]. Nauchno- medicinskij vestnik Central'nogo Chernozem'ya. 2016;65: 27-33. [Article in Russian].

10. Cherednikov EF, Budnevsky AV, Popov AV, Fursov KO. A new opinion on gastroduodenal bleeding prevention in patients with somatic pathology. The EPMA Journal. 2017;8(S1):46.

11. Budnevskiy AV, Popov AV, Cherednikov EF, Kuranosov AYu, Volkova IV, Fursov KO, Martyanova EI. [Erosive and ulcerative lesions of stomach and duodenum in medical patients: prevention of bleeding]. Nauchno-medicinskij vestnik Central'nogo Chernozem'ya. 2016; 65: 64-71. [Article in Russian].

12. Cherednikov EF, Barannikov SV, Maleev YuV, Fursov KO, Litovkina TE, Zakurdaev EI. [Experimental justification of the use of biologically active draining sorbent and plasma enriched by thrombocytes in treatment of bleeding defects of the stomach]. Journal of New Medical Technologies. 2017; 24(2):114-118. [Article in Russian].

13. Cherednikov EF, Batkaev AR, Baev VE. [The reparative regeneration of erosive-ulcerative lesions of the stomach and duodenum in the local treatment of hydrophilic granular sorbents]. System Analysis and Management in Biomedical Systems. 2005;4(2):224-225. [Article in Russian].

14. Cherednikov EF, Gryaznov VN, Baev VE, Gaponenkov DG. [Modeling of a bleeding stomach ulcer]. Problemy sudebnoy mediciny i klinicheskoy praktiki. 1994:17-18. [Article in Russian].

15. Shalimov SA, Radzikhovskiy AP, Keysevich LV. Guide to experimental surgery. M.: Meditsina, 1989:175-176. [In Russian]. 